\title{
A new approach for the vitrification of municipal solid waste incinerator bottom ash by microwave irradiation
}

\author{
Georgia Flesoura ${ }^{1, *}$, Nicole Dilissen ${ }^{1}$, Georgios Dimitrakis ${ }^{2}$, Jef Vleugels ${ }^{1}$, Yiannis Pontikes ${ }^{1}$ \\ ${ }^{1}$ KU Leuven, Department of Materials Engineering, Kasteelpark Arenberg 44, 3001 Heverlee, \\ Belgium. \\ ${ }^{2}$ Department of Chemical and Environmental Engineering, Faculty of Engineering, University of \\ Nottingham, Nottingham NG27 2RD, UK. \\ * georgia.flesoura@,kuleuven.be
}

Keywords: Microwave processing; MSWI bottom ash; Microwave heating; Waste treatment

\begin{abstract}
Encouraging the transition to a circular economy, the valorization of municipal solid waste incinerator (MSWI) bottom ash (BA) has received considerable attention in many processes. In the present work, flash microwave vitrification was effectively realized in a single mode cavity operating at $2.45 \mathrm{GHz}$ within $1.5 \mathrm{~min}$. The closed-loop process was evaluated in terms of energy and power input, treatment time and vitrified bottom ash (VBA) yield rate. The required minimum energy consumption was $\sim 3300$ $\mathrm{kJ} / \mathrm{kg}$. By conducting thermo-electromagnetic multiphysics simulations, the heating mechanism of BA by microwave irradiation was underpinned. This relied on the generation of microwave-induced hot spots inside the material and high power density, in the order of $3 \times 107 \mathrm{~W} / \mathrm{m} 3$, that triggered the onset of BA melting at high heating rates. The inherent cold environment of the microwave cavity, due to the absence of any insulation material, in conjunction with the high silica content of BA promoted the glass forming ability of the melt. This allowed a natural fast cooling of the melt and VBA production, avoiding the cost and environmental impact accompanying conventional quenching. Preliminary characterization of the highly amorphous VBA product was performed and its exothermal heat flow after alkali activation revealed the potential incorporation in the binder of novel building materials.
\end{abstract}

\section{Introduction}

Driven by the approach in Europe that promotes resource recovery and environmental impact reduction, progress has been made on establishing alternative ways of treating waste (European CommissionEnvironment, 2019). In the framework of the circular economy policy, based on 'closing the loop' by utilizing waste for appropriate applications and waste management hierarchy, incineration has been adopted as an attractive waste management technique (European Commission-Environment, 2019.). Through the incineration of municipal solid waste, the volume and mass of waste can significantly be reduced up to $80 \%$ (Wei et al., 2011). At the same time, heat is generated, recovered and converted into energy. However, this is not a complete win-win strategy since it leads to the formation of residues in the incineration plant (Sloot et al., 2001), predominantly municipal solid waste incinerator (MSWI) bottom ash (BA).

For the purpose of waste valorisation, a straightforward route is the utilization of BA in building materials. Nowadays, BA is used as embankment filler, landfill structure, road sub-base material and aggregate in concrete (Blasenbauer et al., 2020), although the presence of heavy metals confines its use in further applications. Thus, prior to recycling, the MSWI ash requires beneficiation, the implementation of which depends on the ash properties and the aimed application (Joseph et al., 2018). The techniques being already implemented on industrial scale are metal extraction, washing and ageing. Vitrification has attracted attention as the most efficient technique for heavy metals immobilization. Industrializing of the vitrification technology is however considered to be an unaffordable route, because it requires a high temperature operation resulting subsequently in a high energy consumption (Joseph et al., 2018).

The European Union's current policy demands for green industrial process technologies (European Parliament and Council, 2018) pledge the use of a sustainable form of energy. In response to this, 
microwave heating comes to the foreground. This has already received considerable attention for waste stabilization, mainly in the field of radioactive waste (Yuan et al., 2017; Zhang et al., 2016). Microwave heating realises essential benefits over conventional heating methods. In essence, microwave heating is volumetric and is associated with high heating rates that cannot be realised by conventional means. As a result, microwave heating can overcome the heat transfer limitations typically associated with processes operating at high temperatures. In addition, electromagnetic waves can interact selectively with the microwave absorber compounds, depending on the material composition and concomitant dielectric properties. Overall, the volumetric and selective mechanism of microwave heating along with the associated high heating rates, typically result in short treatment times and potentially in significant processing benefits compared to conventional thermal treatments (Ferrera-Lorenzo et al., 2014; Menéndez et al., 2010; Xin-Hui et al., 2011).

The synergy between volumetric and selective heating is mainly the case for heterogeneous materials, such as waste and BA, which contain a mixture of compounds that respond differently in an electromagnetic field. Mineral phases with a high dielectric loss factor (e.g. iron oxides (Hotta et al., 2010)) are more susceptible to microwave energy absorption than those with a low loss factor (e.g. quartz, diopside, akermanite, etc. (Rosenholtz and Smith, 1936)), and are thus selectively heated. This was clearly demonstrated in a previous study assessing the dielectric properties of BA subjected to microwave irradiation (Flesoura et al., 2019a). Although BA was found to be a poor microwave absorber at room temperature, the char, produced by the pyrolysis of organic matter, in combination with existing and newly during microwave heating created microwave-absorbing phases like magnetite, metallic iron and aluminum resulted in localized hot spots and high heating rates (Flesoura et al., 2019a). Apart from the material's dielectric properties, the input power density is another parameter affecting the heating mechanism and the overall process. The absorbed or dissipated power, $\mathrm{P}_{\mathrm{d}}$, is directly related to the dielectric loss factor and the local electric field intensity, as given by: (Robinson et al., 2012)

$\mathrm{P}_{\mathrm{d}}=2 \pi \mathrm{f} \varepsilon_{0} \varepsilon^{\prime \prime}|\mathrm{E}|^{2}$

where $\mathrm{f}$ is the microwave frequency $(\mathrm{Hz}), \varepsilon_{0}$ is the permittivity of free space $\left(8.853 * 10^{-12} \mathrm{~F} / \mathrm{m}\right), \varepsilon^{\prime \prime}$ is the dielectric loss factor of a specific mineral phase or material and $\mathrm{E}$ is the electric field strength within the material volume $(\mathrm{V} / \mathrm{m})$. The electric field strength is determined by the design of the microwave applicator and the applied microwave power. Typically, microwave applicators exists in a single mode or multimode configuration. Single mode microwave applicators produce a single electromagnetic resonance wave, resulting in a high local power density, while multimode applicators produce multiple resonance waves and are associated with lower power densities.

To overcome the challenge of the poor microwave absorption of BA at room temperature and establish a controlled heating process, a high electric field intensity, single-mode microwave cavity was used in the current study. To the best of our knowledge, there are no literature reports on the development of a direct microwave BA vitrification process.

The aim of this work was to assess the feasibility of using microwave radiation to vitrify BA and define the extent to which it can be attained. Additionally, the underlying heating mechanism of BA was investigated based on a microwave process parametric study in combination with thermoelectromagnetic multiphysics simulations. The potential to alkali-activate the VBA was also assessed.

\section{Materials and methods \\ 2.1 Material preparation and characterization}

MSWI BA material was provided by Heros Sluiskil BV (The Netherlands). After in-plant quenching (fast cooling) in water and removal of ferrous and non-ferrous metals, the BA was piled up under atmospheric conditions for 2-3 months for stabilization purposes. As-received 0.1-100 mm MSWI BA was dried in a laboratory oven at $105^{\circ} \mathrm{C}$ until no further change of weight could be recorded. The material was crushed in a disk mill (Retsch DM200), followed by milling in a ring mill (Retsch RS200) to a particle size $<100 \mu \mathrm{m}$ (Flesoura et al., 2019a).

Nitrogen gas pycnometry (Quantachrome, MVP-6DC) was used to determine the real density of the BA and VBA powders. The chemical composition of BA and VBA was determined by wavelength 
dispersive X-ray fluorescence (Bruker S8). The mineral composition of BA, VBA and sintered BA (SBA) powders was measured by X-ray diffraction (D2 Phaser Bruker). The amorphous phase content was determined by adding $10 \mathrm{wt} \%$ of analytical-grade crystalline $\mathrm{ZnO}$ to the $\mathrm{BA}$, VBA and SBA as an internal standard. BA, VBA and SBA powder samples were then milled in a McCrone micronizing mill for $7.5 \mathrm{~min}$ in ethanol (purity 99.9\%) with a corundum grinding medium to assure an appropriate fineness for analysis. X-ray diffraction patterns were recorded at room temperature in the $2 \theta$ range from $10^{\circ}$ to $70^{\circ}$, using $\mathrm{Cu} \mathrm{K} \mathrm{K}_{\alpha}$ radiation at an acceleration voltage of $45 \mathrm{kV}$, a current of $30 \mathrm{~mA}$, a step size of $0.020^{\circ}$ and a counting time of $2.5 \mathrm{~s}$ per step. Qualitative analysis was performed using EVA V.3.1 (Bruker AXS) and quantitative analysis using Topas-Academic V.5 (Coelho, 2016), through the Rietveld method. Structural data were taken from the ICSD database.

Considering VBA valorization in alkali activated materials, an evaluation of the reactivity of VBA in terms of heat release, was performed through isothermal calorimetry. A milled VBA sample was prepared by mixing $3 \mathrm{~g}$ of the glass with the activator in ampoules with a Heidolph RZR 2041 mixer at approximately $2500 \mathrm{rpm}$ for 90 seconds. As a sodium silicate activator, a $\mathrm{SiO}_{2} / \mathrm{Na}_{2} \mathrm{O}$ ratio of 1.6 and $\mathrm{H}_{2} \mathrm{O} / \mathrm{Na}_{2} \mathrm{O}$ ratio of 20 was used. The solution/glass powder mass ratio was 0.4 . The heat flow of the sample was measured for 7 days at a constant temperature of $20^{\circ} \mathrm{C}$.

To evaluate the efficiency of vitrification on the leachability of heavy metals from the VBA, leaching test was performed on the VBA and raw BA sample according to EN 12457-4 [19]. The leached heavy metal content was measured by inductively coupled plasma mass spectroscopy (ICP-MS, Agilent 7500 cx) and ion chromatography (IC, Dionex ICS 2000).

\subsection{Microwave processing in a single mode cavity}

Direct microwave vitrification of BA was performed in a $2450 \pm 25 \mathrm{MHz}$ frequency single mode microwave setup. Fig. 1 shows an image of the microwave system used for the experiments, along with a schematic of the constituent components. The system is composed of a microwave generator with a power output of $0-2 \mathrm{~kW}$ connected to a $\mathrm{TE}_{010}$ cavity (SAIREM, France) via a WR430 waveguide. Impedance matching between sample and microwave source, in order to maximize the amount of absorbed incident power, was performed using a 3-stub and a sliding short circuit. $30 \mathrm{~g}$ of loose MSWI BA powder was placed in a quartz tube $(30 \mathrm{~mm}$ height and $40 \mathrm{~mm}$ diameter), positioned along the vertical axis of the cylindrical cavity at the maximum electric field strength. The top of the tube was connected to an off-gas collection system. A $5 \mathrm{ml} / \mathrm{min}$ nitrogen flow was introduced from the top of the tube in order to ensure an inert atmosphere and reducing conditions. Prior to the experiments, the sliding short circuit was positioned to minimize the reflected power and fixed for all the experiments. Only small adjustments of the 3 -stub tuners were performed during the experiments, while both the incident and reflected power were recorded in real time using Agilent power sensors and HomSoft software for energy data logging. The four open viewpoints of the cavity enabled temperature measurements using pyrometers to measure the surface temperature and to detect potential temperature gradients. A singlecolor optris pyrometer (CT LT20, temperature range between $50{ }^{\circ} \mathrm{C}$ and $975{ }^{\circ} \mathrm{C}$ ) was used to measure the temperature on the sample surface, whereas a single-color AMETEK pyrometer (Land, AMETEK, temperature range between $600^{\circ} \mathrm{C}$ and $1600^{\circ} \mathrm{C}$ ) was focused on the hot spots of the sample. Due to the volumetric heating and concomitant temperature gradients inside the material, the temperature profiles are not reported. On the contrary, the temperature distribution throughout the material powder pellet was simulated as explained below. 

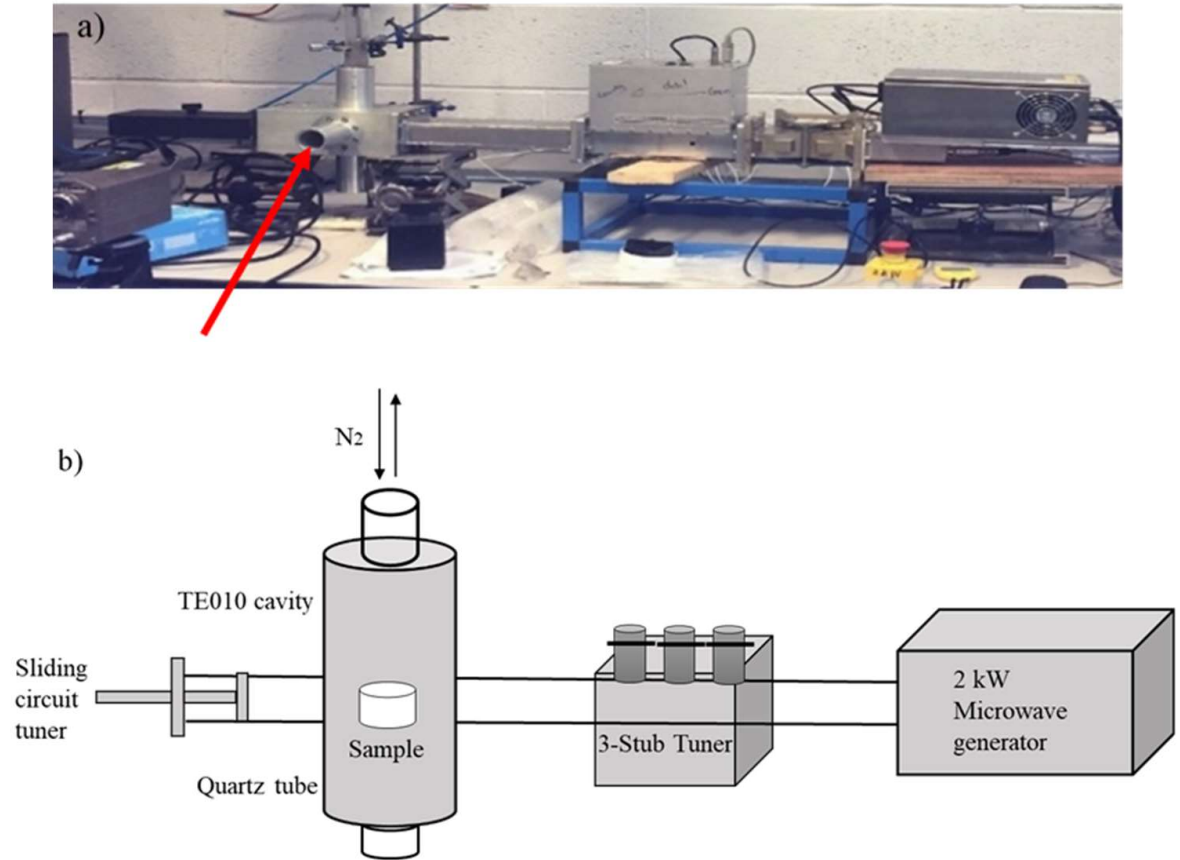

Figure 1: Overview (a) and schematic (b) of the microwave system used for BA vitrification. The red arrow in (a) points out the frontal view inside the cavity, of which a zoomed in version is depicted in Fig. 7.

Table 1: MSWI BA microwave treatment experimental matrix

\begin{tabular}{|c|c|c|c|c|c|}
\hline \multicolumn{2}{|c|}{ Energy input } & \multicolumn{3}{c|}{ Experimental parameters } & Output \\
\hline $\begin{array}{c}\text { Theoretical } \\
\text { Energy } \\
\text { Input } \\
\text { (kJ/kg) }\end{array}$ & $\begin{array}{c}\text { Specific } \\
\text { Energy } \\
\text { Input } \\
\text { (kJ/kg) }\end{array}$ & $\begin{array}{c}\text { Reflected } \\
\text { Power } \\
\text { (W) }\end{array}$ & $\begin{array}{c}\text { Power } \\
\text { Input } \\
\text { (W) }\end{array}$ & $\begin{array}{c}\text { Treatment } \\
\text { time } \\
\text { (min) }\end{array}$ & $\begin{array}{c}\text { VBA yield } \\
(\%)\end{array}$ \\
\hline 2400 & 783 & 159 & 200 & 6 & $0 \pm 0$ \\
2400 & 1501 & 121 & 400 & 3 & $0 \pm 0$ \\
2400 & 1276 & 199 & 600 & 2 & $0 \pm 0$ \\
2400 & 1087 & 309 & 800 & 1.5 & $4 \pm 0$ \\
\hline 4800 & 3405 & 60 & 200 & 12 & $38 \pm 7$ \\
4800 & 3373 & 67 & 400 & 6 & $51 \pm 3$ \\
4800 & 4144 & 56 & 600 & 4 & $43 \pm 2$ \\
4800 & 3268 & 49 & 800 & 3 & $65 \pm 4$ \\
\hline 9600 & 8269 & 24 & 200 & 24 & $64 \pm 2$ \\
9600 & 7998 & 38 & 400 & 12 & $69 \pm 3$ \\
9600 & 8944 & 24 & 600 & 8 & $80 \pm 0$ \\
9600 & 8578 & 35 & 800 & 6 & $86 \pm 0$ \\
\hline 14400 & 12851 & 18 & 200 & 36 & $52 \pm 0$ \\
14400 & 12415 & 38 & 400 & 18 & $66 \pm 0$ \\
14400 & 12802 & 32 & 600 & 12 & $82 \pm 2$ \\
\hline
\end{tabular}

The effect of the electromagnetic power input and exposure time on the MSWI BA to vitrified bottom ash (VBA) conversion yield (presented in the Results and Discussion paragraph), was systematically studied (Table 1). $30 \mathrm{~g}$ MSWI BA powder was used for the microwave vitrification process under an 
applied power ranging from 200 to $800 \mathrm{~W}$ and for 1.5 to 36 minutes. Increasing the power level above $800 \mathrm{~W}$ resulted in plasma formation and a concomitantly high reflected power. Hence, the power level of $800 \mathrm{~W}$ was not applied for more than $6 \mathrm{~min}$. In order to assess the consistency and repeatability of the results, each experiment was duplicated and the reported results are the average values. The specific energy input $(\mathrm{kJ} / \mathrm{kg})$, which is equivalent to the specific energy consumption was calculated as:

Specific Energy Input $(\mathrm{kJ} / \mathrm{kg})=\frac{P(k W) * t(s)}{m(k g)}$

with $\mathrm{P}(\mathrm{kW})$, the effectively absorbed power (or power consumption), which was calculated by subtracting the recorded reflected power from the input power, $\mathrm{t}(\mathrm{s})$, the treatment time and $\mathrm{m}(\mathrm{kg})$, the sample mass. Four experimental parameter combinations with the same theoretical energy input were assessed.

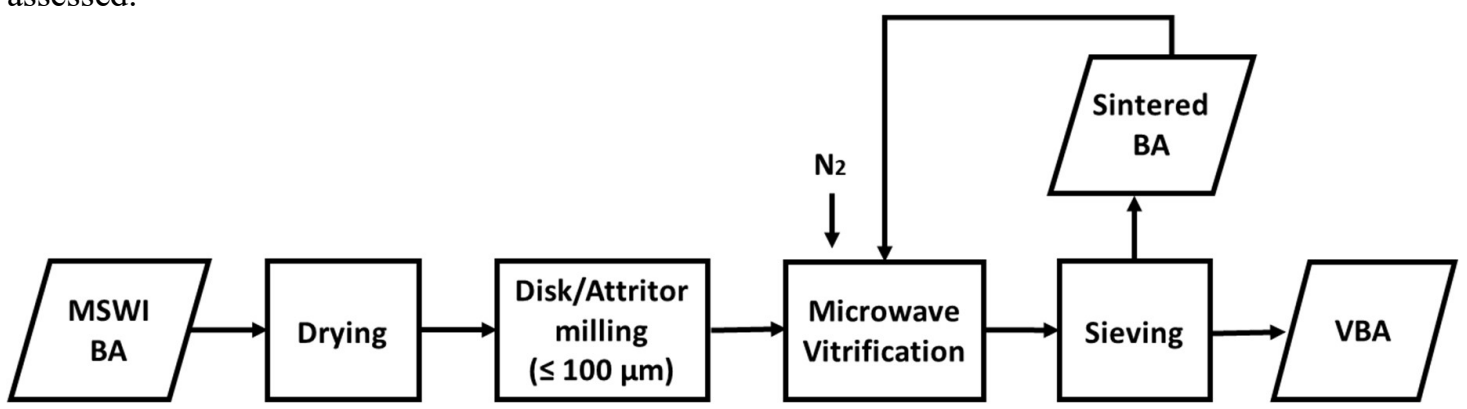

Figure 2: Flowchart of the BA microwave vitrification process.

The flowchart of the microwave vitrification process followed in this study is presented in Fig. 2. The microwave heat treatment resulted in two products, including VBA, in the form of a flattened fully dense glass bead, and surrounding loose SBA powder. At the end of each experiment, manual sieving was performed to separate the VBA bead from the SBA powder. The mass of the produced glass bead was measured and converted into a yield $(\%)$ following the equation, $\left(\mathrm{m}_{\text {bead }} *\left(100 / \mathrm{m}_{\mathrm{BA}}\right)\right)$, where $\mathrm{m}_{\text {bead }}$ was the weight of the glass bead and $\mathrm{m}_{\mathrm{BA}}$ was the initial weight of $\mathrm{BA}$ (equal to $30 \mathrm{~g}$ for all the experiments). The weight losses arising during heating $\mathrm{BA}$, due to loss of water and $-\mathrm{OH}$, dissociation of carbonates, $\mathrm{Fe}^{3+}$ reduction, etc., were not taken into account; the exact temperature of the sample could not be assessed with precision thus results would introduce an error. Hence, the actual VBA yield is higher than the reported values. Of note is that the formation of VBA is directly related to the position of the maximum E-field in the cavity, the power input, the treatment time and the thermal losses.

\subsection{Electromagnetic field and temperature simulations}

The experimental parameters that resulted in the highest vitrification output (VBA yield) were used to simulate the temperature distribution in the powder compact using multiphysics COMSOL simulations, combining microwaves and heat transfer. This concerns the $86 \%$ of VBA yield at $800 \mathrm{~W}$ power input and 6 min treatment time (Table 1). The quartz tube, classified as a transparent material for microwaves, was not considered for the simulations. The electric field strength distribution inside the waveguide and the cavity, in the absence of a BA sample, is presented in Fig. 3a. The quartz tube filled with BA powder was positioned in the centre of the cavity, where the electric field strength was maximum (Fig. 3a). The dimensional parameters were defined for waveguide, cavity, quartz tube and the BA sample, placed in the center of the cavity, in 3D (Fig. 3b). The port for microwaves to enter the waveguide was defined at the waveguide boundary (lower right rectangular surface in Fig. 3b). The multiphysics involved were electromagnetic waves in frequency domain $(\mathrm{emw})$ and heat transfer in solids $(h t)$. In $(\mathrm{emw})$, the wave equation, perfect electric conductor and initial values were predefined and kept unchanged, whereas the port had to be defined. The port type was rectangular, wave excitation was on, port power input was set to $800 \mathrm{~W}$, port phase was 0 rad and port mode was $\mathrm{TE}_{10}$. In $(h t)$, the heat transfer in solids and initial values were predefined. A convective heat flux with external natural convection by air at ambient pressure $(1 \mathrm{~atm})$ and temperature $\left(20^{\circ} \mathrm{C}\right)$ was applied to cavity and waveguide boundaries. Diffuse surface radiation at ambient temperature $\left(20^{\circ} \mathrm{C}\right)$ was applied as boundary condition to the BA surface. The multiphysics software couples the two before-mentioned physics, i.e., the electromagnetic losses 
cause heating and the heating in turn influences the electromagnetic properties. A physics-controlled mesh with extremely fine element size (the finest element size that exists) was used. Within the BA sample, 9 domain point probes were defined at specific x,y,z coordinates, 6 at the edges (e1 to e6) and 3 in the middle ( $\mathrm{m} 1$ to $\mathrm{m} 3$ ), to track the evolution of the temperature at these specific locations of the BA (Fig. 8c). The study was frequency-transient with a frequency of $2.45 \mathrm{GHz}$, a time of 6 min and time step of $0.5 \mathrm{~min}$.

a)

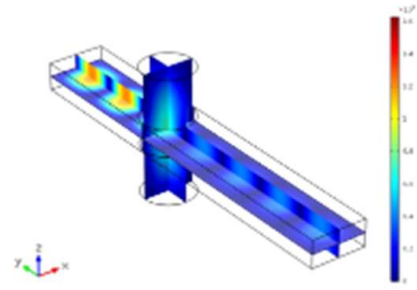

b)

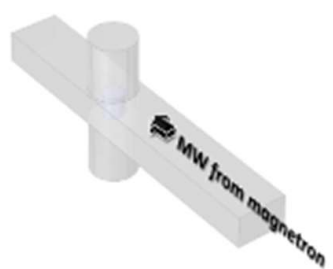

Figure 3: a) Electric field strength $\left(\mathrm{V} / \mathrm{m}^{3}\right)$ distribution in the waveguide (horizontal bar) and cavity (vertical cylinder) without BA sample and b) with BA sample (small cylinder inside the cavity configuration as used for the multiphysics simulations. The magnetron is located on the right hand side of the waveguide. X-Y-Z axes are used as reference, to which the results in Figs. 6 and 7 can be correlated.

Additional parameters used within the multiphysics equations were defined by the materials. The material in the cavity was defined as air, for which the parameters were available in COMSOL in the Built-in Menu. The parameters for the BA sample were provided as input parameters by the user. The relative permittivity, relative permeability and electrical conductivity was used for electromagnetic wave physics, whereas the thermal conductivity, density and heat capacity was necessary for the heat transfer in solids. Surface emissivity was added to the boundary condition of BA. The input data for these parameters are given in Table 2. Relative permittivity and heat capacity depend on temperature, whereas the other parameters were defined as constant. Relative permeability was set to 1 , since BA is non-magnetic (Flesoura et al., 2019a). The electrical conductivity was $0.000197 \mathrm{~S} / \mathrm{m}$, approximated as that of a slag with similar composition (Woollacott et al., 1975). The thermal conductivity of BA was approximated as that of concrete, basalt, glass and set to $1 \mathrm{~W} /(\mathrm{m} . \mathrm{K})$. The density was calculated from mass $(30 \mathrm{~g})$ and volume within the quartz tube $\left(30 \mathrm{~mm}\right.$ height and $40 \mathrm{~mm}$ diameter) to be $800 \mathrm{~kg} / \mathrm{m}^{3}$. Note that this is a powder in the experiments, whereas this was considered as a bulk solid in the simulation. The surface emissivity was chosen as 0.95 .

Table 2: BA properties used in the multiphysics simulations. Equations and constant values are explained in the text.

\begin{tabular}{|l|c|c|c|}
\hline Property & Value & Unit & Physics module \\
\hline Relative permittivity & $\varepsilon^{\prime}(\mathrm{T})-\varepsilon^{\prime \prime}(\mathrm{T}) \mathrm{i}$ & - & $e m w$ \\
\hline Relative permeability & 1 & - & $e m w$ \\
\hline Electrical conductivity & 0.000197 & $\mathrm{~S} / \mathrm{m}$ & $e m w$ \\
\hline Thermal conductivity & 1 & $\mathrm{~W} /(\mathrm{m} . \mathrm{K})$ & $h t$ \\
\hline Density & 800 & $\mathrm{~kg} / \mathrm{m}^{3}$ & $h t$ \\
\hline Heat capacity & $\mathrm{C}_{\mathrm{p}}(\mathrm{T})$ & $\mathrm{J} /(\mathrm{kg} \cdot \mathrm{K})$ & $h t$ \\
\hline Surface emissivity & 0.95 & - & Diffuse surface \\
\hline
\end{tabular}

The temperature-dependent equation for the relative permittivity consists of the dielectric constant $\varepsilon^{\prime}(\mathrm{T})$ and dielectric loss factor $\varepsilon^{\prime \prime}(\mathrm{T})$ (Table 3), that are based on the dielectric measurements from (Flesoura et al., 2019a). A window type function was used for $\varepsilon^{\prime}(\mathrm{T})$ and $\varepsilon^{\prime \prime}(\mathrm{T})$ with temperature intervals.

Table 3: Functions used for the simulations of $\varepsilon^{\prime}(\mathrm{T})$ and $\varepsilon^{\prime \prime}(\mathrm{T})$ with temperature intervals.

\begin{tabular}{|c|c|l|}
\hline $\mathbf{T}_{\text {Start }}(\mathbf{K})$ & $\mathbf{T}_{\text {End }}(\mathbf{K})$ & $\mathbf{\varepsilon}^{\prime}(\mathbf{T})$ \\
\hline 314 & 588 & $0.0005 \times T+2.1659$ \\
\hline
\end{tabular}




\begin{tabular}{|c|c|l|}
\hline 588 & 670 & $0.0138 \times T-5.4822$ \\
\hline 670 & 1108 & $0.0025 \times T+2.1568$ \\
\hline 1108 & 1700 & $-3.1818 \cdot 10^{-5} \times T^{2}+0.0831 \times T-48.38$ \\
\hline $\mathbf{T}_{\text {Start }}(\mathbf{K})$ & $\mathbf{T}_{\text {End }}(\mathbf{K})$ & $\mathbf{\varepsilon}^{\prime \prime} \mathbf{( T )}$ \\
\hline 314 & 573 & $2 \cdot 10^{-7} \times T^{2}-0.0001 \times T+0.024$ \\
\hline 573 & 670 & $0.0098 \times T-5.6286$ \\
\hline 670 & 948 & $0.0012 \times T+0.092$ \\
\hline 948 & 1108 & $0.0086 \times T-7.0767$ \\
\hline 1108 & 1338 & $0.026 \times T-26.195$ \\
\hline
\end{tabular}

\section{Results \& Discussion}

\subsection{Assessment of microwave vitrification of MSWI BA}

The microwave heat treatment resulted in two products, i.e. a fully dense VBA glass bead and agglomerated and loose SBA powder, as shown in Fig. 4, for the BA heat treated at 400W for 6 minutes. The VBA yield, is summarized in Table 1 .

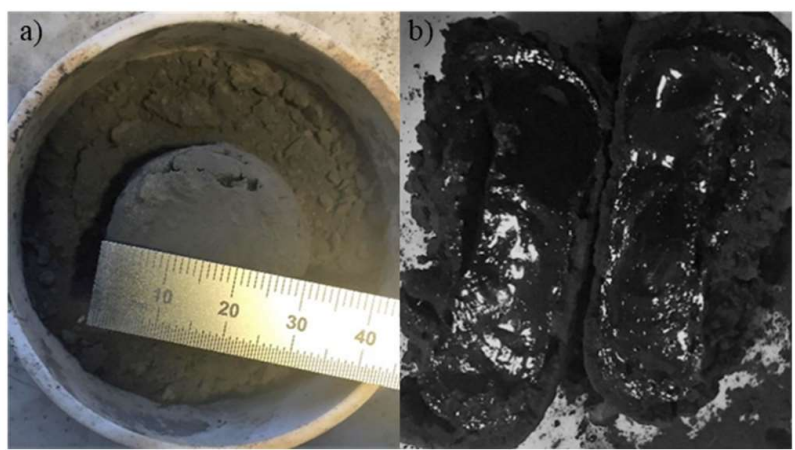

Figure 4: Microwave processed BA products (400W for 6min); (a) VBA bead and SBA powder and (b) VBA glass bead halves after fracturing.

The evolution of the glass yield (\%) as a function of the heating time at 4 input power levels is presented in Figure 5. The glass yield varied from $0 \%$ to $86 \%$, depending on the process conditions. It is clear that the yield reaches a saturation level $80 \%$ at power inputs of 600 and $800 \mathrm{~W}$. The scatter plots are sigmoidal as a function of time and shift to shorter treatment times at higher input power levels.

The intrinsic microwave heating mechanism of BA was revealed by the effect of the calculated specific energy input and power input on the VBA yield and was confirmed by the simulation results, presented in section 3.2. Fig. 6 shows the evolution of the VBA yield as a function of the specific energy input at different levels of applied power input. 


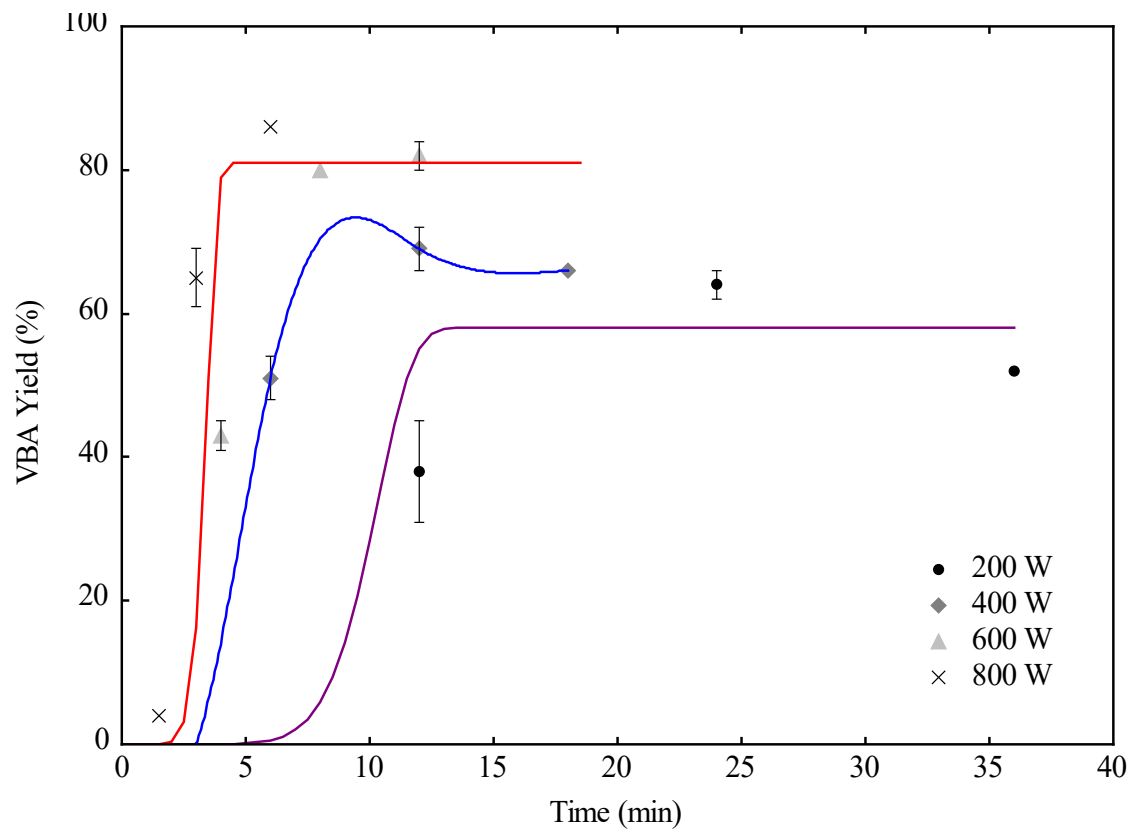

Figure 5: Effect of heating time and power level on the glass bead production during microwave processing of $30 \mathrm{~g} \mathrm{BA}$ in a single mode cavity.

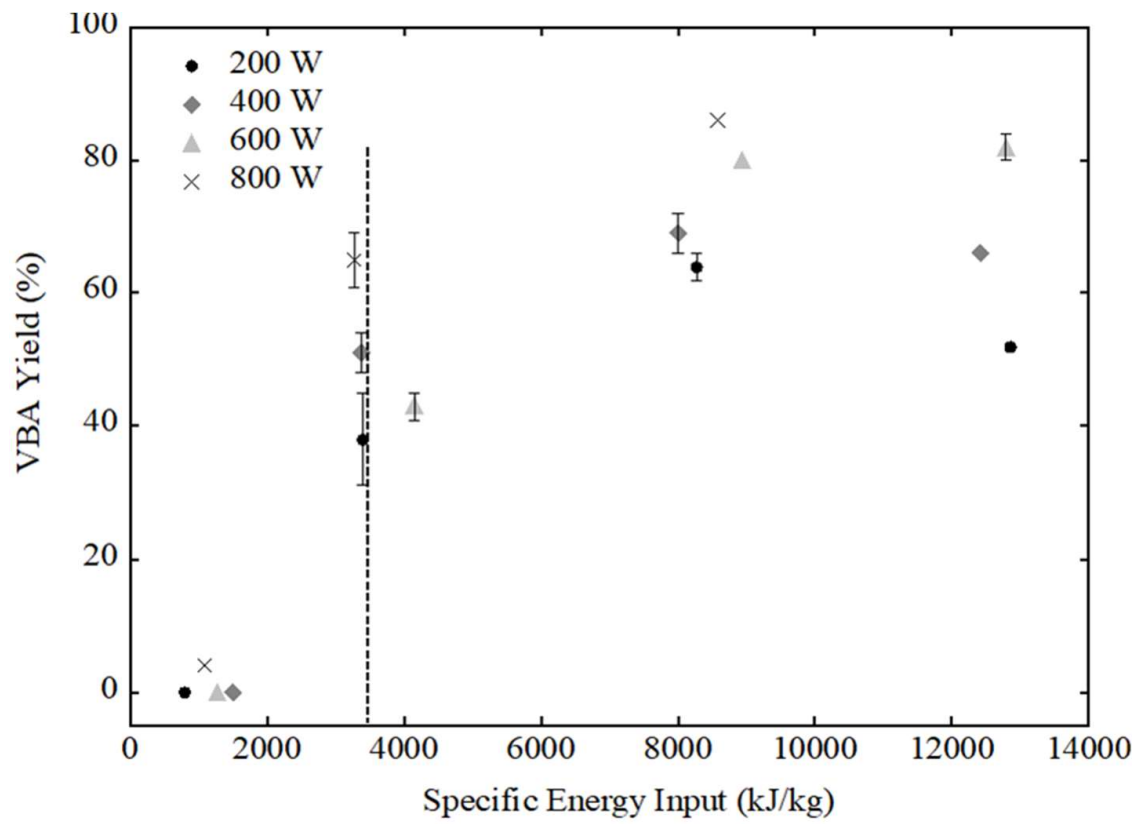

Figure 6: Effect of the specific energy input on the VBA production yield during microwave processing of $30 \mathrm{~g} \mathrm{BA}$ samples in a single mode cavity. The dotted line indicates the sigmoidal trend of the scatter plots, near the value of the threshold energy input.

A yield of $63 \%$ was obtained with an energy input of $\sim 3300 \mathrm{~kJ} / \mathrm{kg}$. Further increasing the energy input up to $\sim 8600 \mathrm{~kJ} / \mathrm{kg}$ allowed to increase the VBA yield up to a maximum of $86 \%$, implying that the absence of thermal insulation material around the quartz tube and the surrounding cold inherent environment of the cavity hindered complete vitrification of the complete powder bed due to the axial and radial thermal gradients (as explained in depth in section 3.2). For comparison, an energy consumption of $2600 \mathrm{~kJ} / \mathrm{kg}$ was reported for MSWI fly ash vitrification by thermal plasma melting (Huang et al., 2014). 
A threshold energy input of $\sim 3300 \mathrm{~kJ} / \mathrm{kg}$, as indicated by the vertical line in Fig. 6, was required to initiate vitrification which was even possible with a power input of only $200 \mathrm{~W}$. The maximum yield however was reached faster when using a higher input power, specifically at $600 \mathrm{~W}$ and $800 \mathrm{~W}$, as indicated by the shift of the sigmoidal curves in Fig. 5. On the contrary, BA vitrification did not take place at $200 \mathrm{~W}, 400 \mathrm{~W}$ and $600 \mathrm{~W}$ after 6,3 and 2 min respectively. This clearly indicates the vitrification of VBA is energy density controlled, and conversion goes faster at higher power input, providing the threshold energy level is reached. A higher power input at constant duration also results in a larger volume of the powder compact reaching this threshold, resulting in a higher yield, explaining the slightly higher yields at $800 \mathrm{~W}$ power levels.

As a remark, there is no linear trend between the total energy input and the VBA yield, as higher energy dissipation did not lead to higher yields (see Fig. 6). Additionally, it is worth highlighting that the same theoretical energy input for different power-time combinations (see Table 1) did not result in the same VBA yield, implying the BA microwave vitrification process was not in thermodynamic equilibrium. Microwave BA vitrification was conversely favored by a high power density, i.e. high applied power levels (e.g for $600 \mathrm{~W}$ and $800 \mathrm{~W}$ ) for shorter times (Fig. 6).

A potential reason for the above lies in the non-thermal interactions between BA and microwave irradiation by microplasma generation (Hopwood et al., 2014). As mentioned, BA is a mixture of various mineral phases and organic matter that respond differently when subjected to electromagnetic energy. Localized hot spots, known as microplasmas, are initiated in the char, produced by the pyrolysis of organic matter around $320^{\circ} \mathrm{C}$ and in iron metallic particles that are formed during the reduction of iron oxides. These randomly located microplasmas were visible in the form of small sparks or hot spots that exhibited a thermal runaway, which lasted only a couple of seconds. Visible evidence of this phenomenon when realizing BA vitrification at $800 \mathrm{~W}$ is shown in Fig. 7, which presents in high magnification the quartz tube filled with BA powder, when treated at $800 \mathrm{~W}$ for $1.5 \mathrm{~min}$. The photograph was taken from the frontal viewpoint of the cavity, where the arrow in Fig. 1 is placed. Such microwave-driven micro-plasmas were reported to exhibit in all carbon materials (Menéndez eal., 2011).

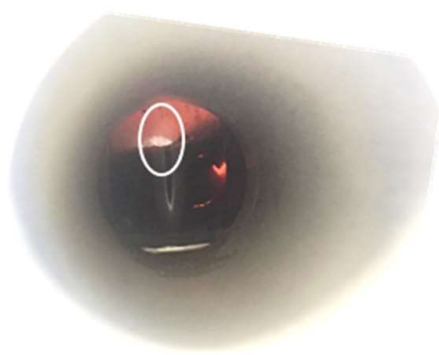

Figure 7: Frontal view inside the cavity, showing the quartz tube filled with BA powder, when treated at $800 \mathrm{~W}$ for $1.5 \mathrm{~min}$, evidencing a local hot spot or microplasma (circled area).

At the microwave induced hot spots, favored also by the lack of oxygen and the inert gas use, vitrification initiated. This potentially explains why the process appears to be benefited more by the magnitude of the applied power rather than the total energy input. The above described phenomenon can be better assessed by taking into account the Eq. (3), indicating that the heating rate $(\Delta T / \Delta t)$ is proportional to the power density. Therefore, when the absorbed microwave energy is increased, the power density increases as well, giving rise to higher heating rates (Shang et al., 2006).

$\frac{\Delta T}{\Delta t}=\frac{P d}{\rho C p}$

with $\mathrm{T}$, the temperature $\left({ }^{\circ} \mathrm{C}\right), \mathrm{t}$, the time $(\mathrm{s}), \mathrm{P}_{\mathrm{d}}$, the power density $\left(\mathrm{W} / \mathrm{m}^{3}\right), \rho\left(\mathrm{kg} / \mathrm{m}^{3}\right)$, the density and $\mathrm{C}_{\mathrm{p}}(\mathrm{J} / \mathrm{kg} \cdot \mathrm{K})$, the heat capacity of the material. The inherent difficulty of accurate temperature measurements in microwave configurations required simulations in order to visualize the electric field, power density and the resulting temperature distribution throughout the BA sample (Kappe, 2013). 


\subsection{Electromagnetic field and temperature distribution simulation}

The electromagnetic field along with heat transfer simulations were performed for a $800 \mathrm{~W}$ power input. It should be noted that although the simulation results (Fig. 8 and Fig. 9) correspond to an instant time, the electric field and power density distributions change according to the temperature increase and to the associated dielectric properties of BA material. Once the magnetron was switched on and $800 \mathrm{~W}$ power was forwarded to the BA powder bed, the dielectric properties instantly changed (Flesoura et al., 2019a) causing a shift of the electric field peak from the center of the cavity (Fig. 3a) to the edge of the sample (Fig. 8a, $\mathrm{t}=0 \mathrm{~min}$ ). In addition, the slight increase of the dielectric properties at room temperature (Fig. $8 \mathrm{c}, \mathrm{t}=0 \mathrm{~min}$ ) only slightly increased the electric field strength from $1.6 \times 10^{5} \mathrm{~V} / \mathrm{m}$ to $2.4 \times 10^{4} \mathrm{~V} / \mathrm{m}$ (Fig. $8 \mathrm{a}, \mathrm{t}=0 \mathrm{~min}$ ). Similarly, as the power density is proportional to the square of the electric field strength and to the material's loss factor (Eq. 1), it only reached a moderate value of $0.5 \times 10^{6} \mathrm{~W} / \mathrm{m}^{3}$ at the edge of the BA powder bed (Fig. $8 \mathrm{a}, \mathrm{t}=0 \mathrm{~min}$ ). Within $0.5 \mathrm{~min}$ of constant power input, the highest achieved temperature was found to be equal to almost $300{ }^{\circ} \mathrm{C}$, at the position where the field strength and power density created a hotspot (Fig. $8 \mathrm{c}, \mathrm{t}=0.5 \mathrm{~min}$ ). This is potentially explained by the substantial effect of the field strength on the absorbed power and temperature distribution, since the dielectric properties of BA were hardly affected in this temperature range. This behavior complied with the slow evolution of the experimentally measured dielectric properties of BA up to $320{ }^{\circ} \mathrm{C}$ (Flesoura et al., 2019a). Beyond $0.5 \mathrm{~min}(30 \mathrm{~s})$, crucial changes governed the evolution of the temperature and power density. As previously reported (Flesoura et al., 2019a), char production around $320{ }^{\circ} \mathrm{C}$ promoted the generation of the localized hotspots, due to microplasma formations. These hot spots can be denoted at location $\mathrm{m} 1$ and $\mathrm{m} 3$ along the $\mathrm{y}$ axis (height of the sample) in Fig. 8c, $\mathrm{t}=1 \mathrm{~min}$, in which the temperature instantly raised to $1530{ }^{\circ} \mathrm{C}$ and $1200{ }^{\circ} \mathrm{C}$ respectively, inducing the onset of BA melting. Based on FactSage calculations, using the FactPS and FactOxid database, the melting temperature of BA was estimated to be between $1200{ }^{\circ} \mathrm{C}$ and $1250{ }^{\circ} \mathrm{C}$. Although the bulk temperature of the BA was higher than the edges (Fig. 8c, $\mathrm{t}=1 \mathrm{~min}$, points $\mathrm{e} 3$ and e2), creating an 'inverse' temperature gradient (Shepherd et al., 2018), the sample was heated volumetrically when $\mathrm{t}=1 \mathrm{~min}$ (Fig. $8 \mathrm{c}$ and Fig. 9a). A power density equal to $2-3 \times 10^{7} \mathrm{~V} / \mathrm{m}$ was sufficient to induce flash BA melting within a few seconds (Fig. 9a and b). Further increase in treatment time $(\mathrm{t}=1.5 \mathrm{~min})$ did not contribute to a significant temperature rise (see Fig. 9a), as the highest achieved temperature was $1590^{\circ} \mathrm{C}$ (Fig. $8 \mathrm{c}, \mathrm{t}=1.5 \mathrm{~min}$, e4 point). The existence of molten BA beyond 1 and $1.5 \mathrm{~min}$, as predicted by the simulation results, was proven by the experiment performed at $800 \mathrm{~W}$ power input for $1.5 \mathrm{~min}$ which delivered a $4 \mathrm{wt} \%$ VBA yield. According to Fig. 9b, thermal equilibrium was achieved in the system beyond $1.5 \mathrm{~min}$, implying an equal amount of absorbed energy and loss to the cold surrounding environment by radiation and convection. The longer dwell time however resulted in an increased conversion, i.e. growth of the viscous glass bead, with a total yield of $86 \mathrm{wt} \%$ after 6 minutes (Table 1). The natural quenching (fast cooling) in the thermal insulation-free microwave cavity was fast enough to avoid glass forming during cooling. 


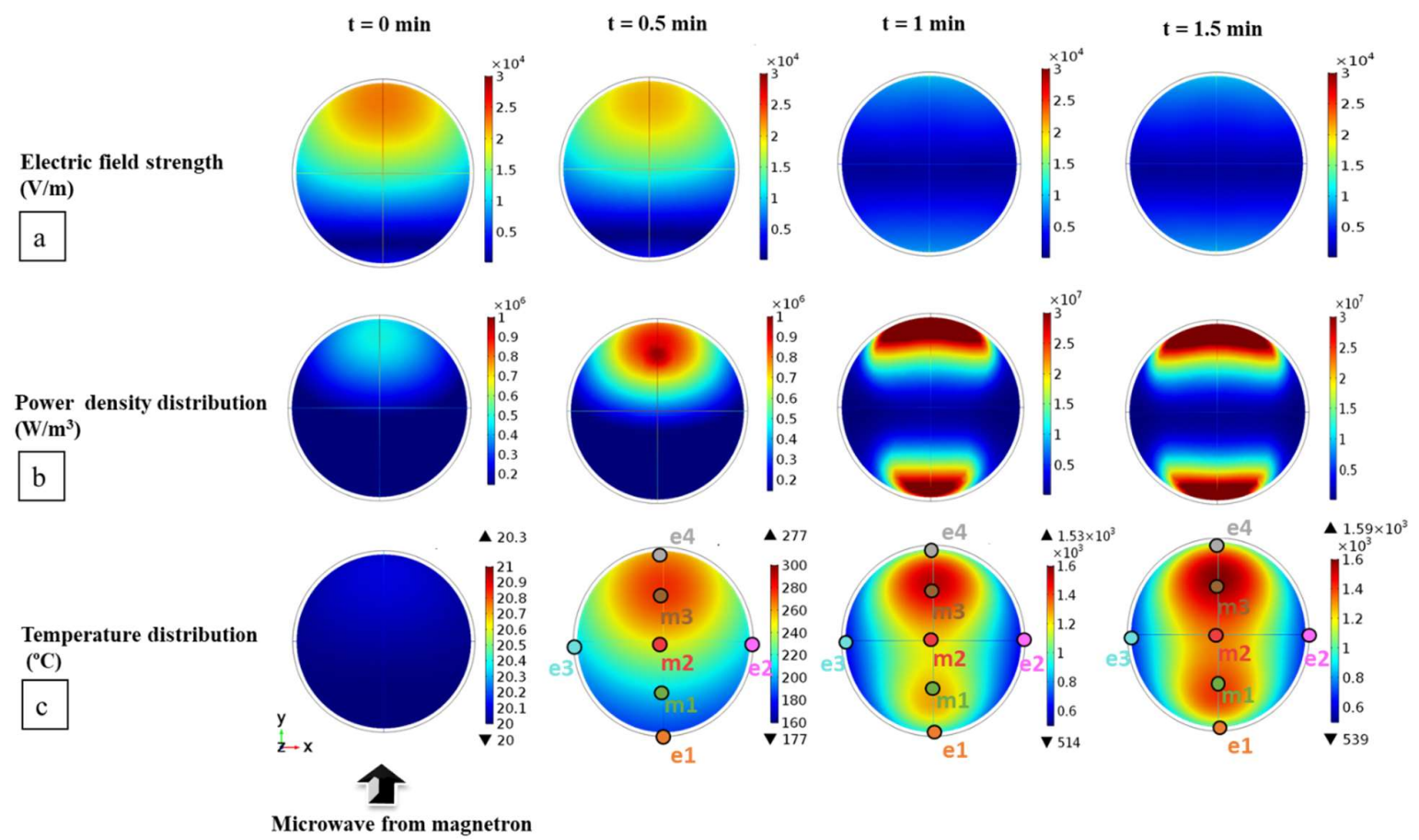

Figure 8: Simulated electric field strength (a), power density distribution (b) and temperature distribution (c) during microwave vitrification of BA at $800 \mathrm{~W}$ after $0 \mathrm{~min}, 0.5 \mathrm{~min}, 1 \mathrm{~min}$ and $1.5 \mathrm{~min}$ processing time.
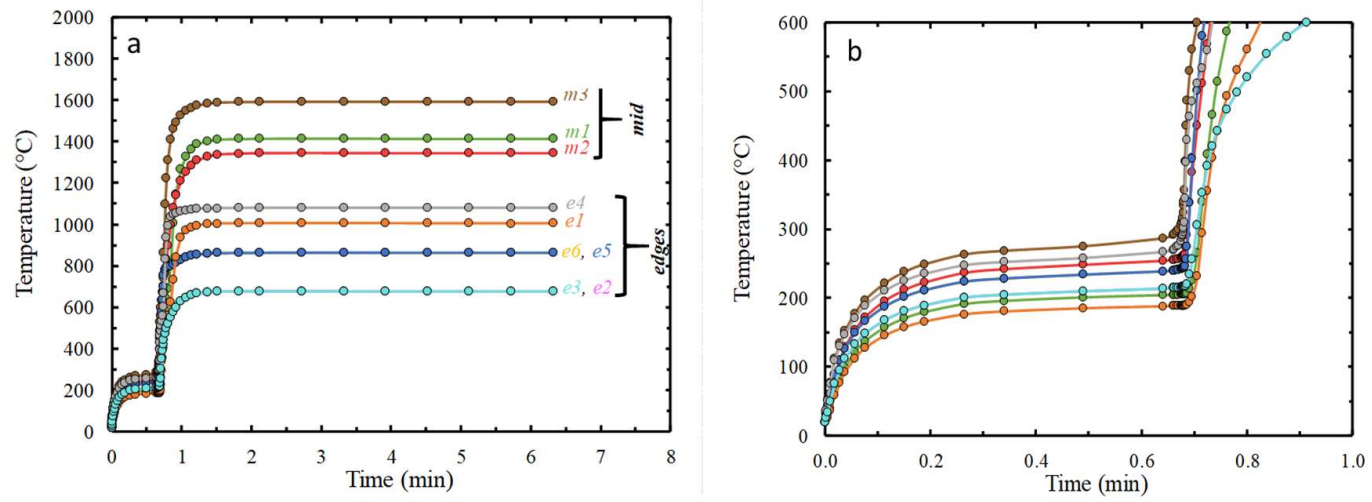

Figure 9: Simulated heating profile during microwave vitrification of BA at $800 \mathrm{~W}$ (a) during the first 6 min and (b) the first minute and the first The e1-e6 and m1-m3 locations are marked in Fig. $8(\mathrm{c})$.

\subsection{Characterization of the microwave MSWI BA products 3.3.1 Characterization of microwave produced VBA}

The chemical composition of the BA starting material and the average composition of the VBA produced under the different process conditions summarised in Table1, which is close to the overall BA composition, is presented in Table 4. VBA is mainly composed of $\mathrm{SiO}_{2}, \mathrm{CaO}, \mathrm{Fe}_{2} \mathrm{O}_{3}, \mathrm{Al}_{2} \mathrm{O}_{3}$ and $\mathrm{MgO}$ (expressed as oxides).

Table 4: Chemical composition of the raw BA starting powder and microwave VBA in wt $\%$, as measured by WDS-XRF (estimated relative error is $10 \%$; expressed as oxides), the amount of amorphous phase in $\mathrm{wt} \%$, and density in $\mathrm{g} / \mathrm{cm}^{3}$. The VBA composition is the average composition of the VBA beads obtained from the experiments described in Table 1 (basically 12 beads and their duplicates). 


\begin{tabular}{|c|c|c|c|c|c|c|c|c|c|c|}
\hline & $\begin{array}{c}\mathrm{SiO}_{2} \\
\left(\mathrm{wt}^{2} \%\right)\end{array}$ & $\begin{array}{c}\mathrm{CaO} \\
(\mathrm{wt} \%)\end{array}$ & $\begin{array}{l}\mathrm{Fe}_{2} \mathrm{O}_{3} \\
(\mathrm{wt} \%)\end{array}$ & $\begin{array}{l}\mathrm{Al}_{2} \mathrm{O}_{3} \\
(\mathrm{wt} \%)\end{array}$ & $\begin{array}{l}\mathrm{MgO} \\
(\mathrm{wt} \%)\end{array}$ & $\begin{array}{l}\mathrm{Na}_{2} \mathrm{O} \\
(\mathrm{wt} \%)\end{array}$ & $\begin{array}{l}\text { Other } \\
(w t \%)\end{array}$ & $\begin{array}{c}\text { Amorphous } \\
\text { fraction } \\
(\mathrm{wt} \%)\end{array}$ & $\begin{array}{l}\text { Density } \\
\left(\mathrm{g} / \mathrm{cm}^{3}\right)\end{array}$ & LOI \\
\hline Raw BA & 47.80 & 18.30 & 10.00 & 9.39 & 2.04 & 4.08 & 8.39 & 69.2 & 2.6 & 7.5 \\
\hline Average & 49.63 & 20.24 & 11.26 & 9.92 & 2.47 & 0.93 & 5.55 & 90.0 & 2.7 & 0.2 \\
\hline
\end{tabular}

The average mineralogical composition of the microwave VBA produced under different process conditions is presented in Table 5. The crystalline phases embedded in the glass matrix are mainly anorthite, corundum, clinopyroxene, gehlenite quartz, wollastonite and metallic iron. All VBA products presented a high amorphous content, varying from $82 \mathrm{wt} \%$ to $95.4 \mathrm{wt} \%$. The VBA products formed at $200 \mathrm{~W}$ had the lowest amorphous content, between $82 \mathrm{wt} \%$ and $84.8 \mathrm{wt} \%$, whereas the VBA products made at $600 \mathrm{~W}$ and $800 \mathrm{~W}$ had the highest glass content (between $91 \mathrm{wt} \%$ and $95.4 \mathrm{wt} \%$ ). All VBA materials demonstrated an increased glass content compared to the starting BA powder (Table 4), which is associated with the high glass forming ability of the BA starting powder in the presence of a silicate network. The high silica content results in a melt with high viscosity and configurational entropy that shows increased resistance to nucleation and crystallisation and therefore produces a glassy material as experimentally confirmed (Mysen and Richet, 2005).

Table 5: Average mineralogical composition of the microwave VBA in wt $\%$, as measured by XRD and quantified by Topas (estimated relative error: $10 \%$ ) and mineralogical composition of the microwave VBA-600-8, VBA-800-6 and VBA-600-12 samples as the ones with yield over $80 \%$. The VBA composition is the average composition of the VBA beads obtained from the experiments described in Table 1 (basically 12 beads and their duplicates) and the composition of the VBA-600-8, VBA-800-6 and VBA-600-12 is the average of the duplicates.

\begin{tabular}{|c|c|c|c|c|c|c|c|c|}
\hline & Amorphous & Anorthite & Corundum & Clinopyroxene & Gehlenite & Iron & Quartz & Wollastonite \\
\hline Average VBA & $90.0 \pm 4.3$ & $1.1 \pm 0.6$ & $1.2 \pm 0.5$ & $2.8 \pm 1.9$ & $1.0 \pm 0.6$ & $1.1 \pm 0.6$ & $0.4 \pm 0.2$ & $2.1 \pm 0.8$ \\
\hline VBA-600-8 & $93.0 \pm 0.0$ & $0.5 \pm 0.1$ & $0.9 \pm 0.2$ & $2.8 \pm 0.3$ & $1.0 \pm 0.1$ & $0.9 \pm 0.1$ & $0.2 \pm 0.1$ & $0.7 \pm 0.2$ \\
\hline VBA-800-6 & $94.3 \pm 0.2$ & $0.5 \pm 0.3$ & $0.4 \pm 0.1$ & $1.7 \pm 0.2$ & $0.4 \pm 0.1$ & $1.3 \pm 0.2$ & $0.6 \pm 0.1$ & $0.6 \pm 0.2$ \\
\hline VBA-600-12 & $90.8 \pm 0.1$ & $1.2 \pm 0.2$ & $2.1 \pm 0.2$ & $3.1 \pm 0.3$ & $0.4 \pm 0.1$ & $1.2 \pm 0.1$ & $0.4 \pm 0.1$ & $1.5 \pm 0.2$ \\
\hline
\end{tabular}

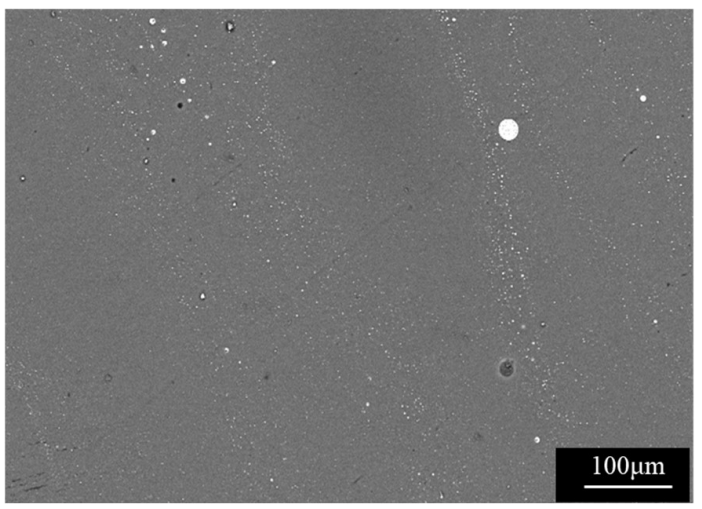

Figure 10: EPMA-BSE image of the amorphous region of the VBA-800-6 material. 
Table 6: EPMA-WDX compositional analysis of the amorphous phase in $w t \%$ ( \pm standard deviation). At least 10 points were measured for the analysis.

\begin{tabular}{|c|c|c|c|c|c|c|}
\hline & $\mathrm{SiO}_{2}$ & $\mathrm{CaO}$ & $\mathrm{Fe}$ & $\mathrm{Al}_{2} \mathrm{O}_{3}$ & $\mathrm{MgO}$ & $\mathrm{Na}_{2} \mathrm{O}$ \\
\hline VBA-800-6 & $54.9 \pm 0.5$ & $17.8 \pm 0.2$ & $4.5 \pm 1.8$ & $8.8 \pm 0.2$ & $1.3 \pm 0.3$ & $1.9 \pm 0.4$ \\
\hline
\end{tabular}

Microstructural analysis was performed on the VBA produced at $800 \mathrm{~W}$ for $6 \mathrm{~min}$ (VBA-800-6). This material was chosen because of the high glass yield $(86 \mathrm{wt} \%)$ and the increased amorphous content (94 wt\%). The EPMA image, presented in Figure 10, suggests a homogeneous glassy phase, absence of crystals, with dispersed iron metallic particles presented as the white dispersed phase. The formation of a calcium aluminosilicate $(\mathrm{Ca}-\mathrm{Al}-\mathrm{Si})$ glassy matrix with dispersed iron $(\mathrm{Fe})$, which has been presented in Tables 4 and 5, is also confirmed by the micro-chemical analysis employed on the amorphous phase. Table 6 reports the average composition of at least 10 point analyses on the amorphous region.

\subsubsection{Characterization of microwave produced sintered BA}

SBA, i.e. the remaining BA powder without the VBA glass bead (part 3, Fig.11), could be recirculated in the microwave vitrification process (Fig. 2) to be vitrified. As a proof of concept, the sintered BA powder, $30 \mathrm{~g}$ of residual BA coming from the experiments performed at $800 \mathrm{~W}$ for $6 \mathrm{~min}$, was used for microwave vitrification.

Aiming to estimate the temperature at which the sintered BA powder has been formed, the XRD pattern was compared with those of HTXRD measurements recorded under reducing atmosphere, reported elsewhere (Flesoura et al., 2019a). The formation of $\mathrm{Fe}_{3} \mathrm{O}_{4}$ and $\mathrm{Fe}^{0}$ (Fig. 11) indicates that the reached temperature of the SBA powder (SBA-800-6) was in the $800-900{ }^{\circ} \mathrm{C}$ range, being also in accordance with the simulated temperature for point $\mathrm{e} 3$ and e 2 presented in Fig $8 \mathrm{c}, \mathrm{t}=1.5 \mathrm{~min}$. The mineral phases that have been formed in the SBA powder (mainly $\mathrm{Fe}_{3} \mathrm{O}_{4}, \mathrm{FeO}$ and $\mathrm{Fe}^{0}$ ) have been reported to be more prone to microwave energy absorption than the ones present in BA (Flesoura et al., 2019a). The iron oxides in SBA allowed the almost complete $(86 \mathrm{wt} \%)$ vitrification of the sintered BA within 3 min, instead of $6 \mathrm{~min}$. The decreased processing time contributed to a lower energy consumption, equivalent to $3438 \mathrm{~kJ} / \mathrm{kg}$.

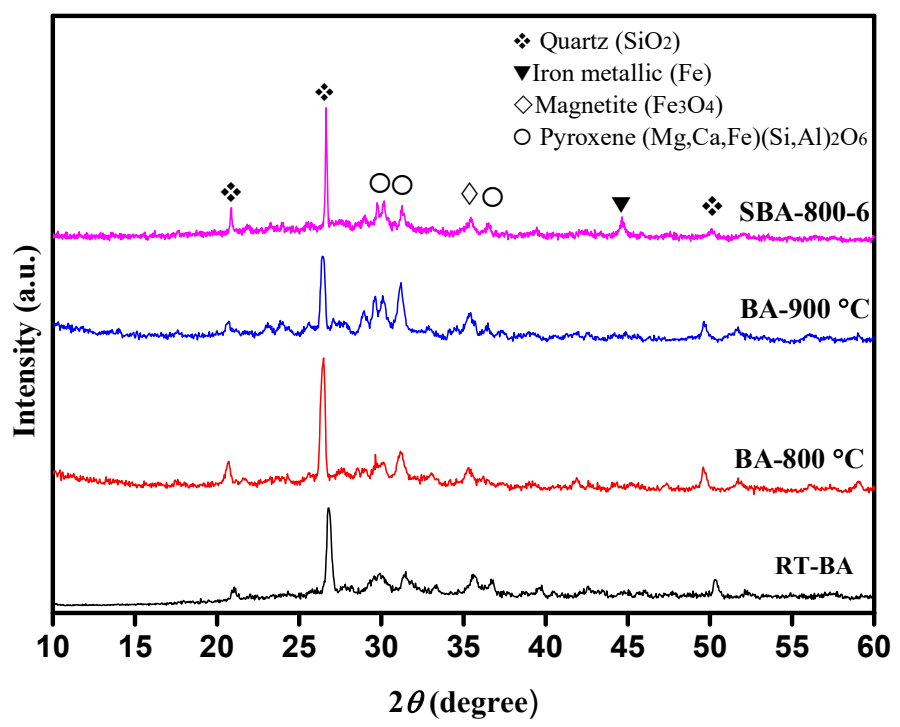

Figure 11: XRD patterns of BA at room temperature (RT-BA), SBA-800-6, and BA at $800^{\circ} \mathrm{C}$ and $900^{\circ} \mathrm{C}$ (Flesoura et al., 2019a). 
Exploring valorization routes for the produced VBA, the potential to be used as a precursor for the synthesis of alkali activated materials, e.g. inorganic polymers, was assessed through isothermal calorimetry measurements. Figure 12 shows the heat flow of an alkali activated mixture of VBA-8006 (produced as described in section 3.3.2). One exothermic peak is observed immediately after mixing VBA with the activating solution. This peak could be assigned to wetting (Onisei et al., 2015) and dissolution reactions. Fast kinetics have also been observed in other silica-rich glasses with similar chemical composition that can be considered as reference materials. Alkali activating microsilica and rice husk ash (Gao et al., 2017), ground granulated blast furnace slag with fly ash mixtures (Alonso and Palomo, 2001; Kumar et al., 2010; Luukkonen et al., 2018) and synthetic VBA (Flesoura et al., 2019b) also generated a wetting and dissolution exothermic peak within the first few minutes of mixing.
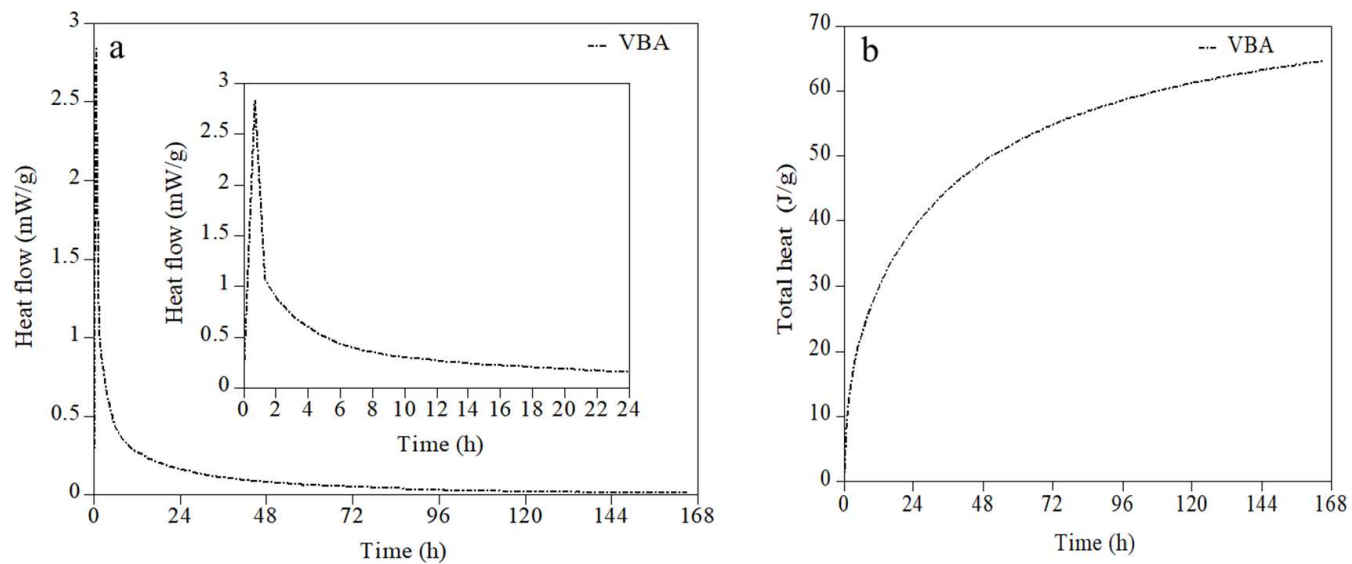

Figure 12: Heat flow and detail of the first 24 hours (a) and total heat (b) in isothermal calorimetry at $20{ }^{\circ} \mathrm{C}$ during the first 7 days after mixing, normalized by the weight of VBA-800-6.

The leaching behavior of the VBA-800-6 was compared to BA sample, in order to identify the concentration of heavy metals in VBA and assure its use in construction materials. The leaching data are presented in Table 7.

Table 7: Leaching test results on raw BA and VBA samples $(\mathrm{mg} / \mathrm{kg})$.

$\begin{array}{ccccc}\text { Element } & \begin{array}{c}\text { Limit values for } \\ \text { non-hazardous waste } \\ (E N ~ 12457-4)\end{array} & \begin{array}{c}\text { Limit values for } \\ \text { inert waste }\end{array} & \text { Raw BA } & \text { VBA } \\ & \text { (EN 12457-4) } & & \end{array}$

\begin{tabular}{ccccc}
\hline Antimony & 0.7 & 0.06 & 0.1987 & 0.0182 \\
\hline Arsenic & 2 & 0.5 & 0.0541 & 0.0049 \\
\hline Barium & 100 & 20 & 4.3125 & 0.0173 \\
\hline Cadmium & 1 & 0.04 & 0.0333 & 0.0006 \\
\hline Chromium & 10 & 0.5 & 0.8446 & 0.0053 \\
\hline Copper & 50 & 2 & 6.5525 & 0.0383 \\
\hline Lead & 10 & 0.2 & 1.8998 & 0.0153 \\
\hline Molybdenum & 10 & 0.5 & 0.0691 & $<0.0033$ \\
\hline Nickel & 10 & 0.4 & 0.4587 & $<0.0014$ \\
\hline Zinc & 50 & 4 & 9.4422 & 0.0203 \\
\hline
\end{tabular}

The amount of leached antimony, arsenic, chromium, copper, molybdenum, lead, nickel and zinc from BA do not comply with the limits for inert waste (EN 12457-7) (see Table 7), whereas the VBA is much more resistant to leaching after vitrification and can even be classified as a non-hazardous waste. This could be assigned to the volatilization of some heavy metals (e.g. arsenic, zinc, lead) during vitrification, which is influenced by the complexing ligands and their volatilization tendency (Stabile et al., 2019), 
and the immobilization of some elements (e.g. zinc, copper, nickel, chromium) in the glassy VBA matrix.

The findings presented in this work shed light on the microwave processing of BA, forming the baseline for a potentially viable upscaling process in a multimode furnace that allows a high throughput.

\section{Conclusions}

The feasibility and extent to which direct microwave BA vitrification can be realized as a waste management technique was studied. The effect of microwave power and treatment time on the VBA yield was assessed. A flash microwave process of the order of some seconds, was sufficient to initiate BA feedstock vitrification with an energy requirement equal to $3300 \mathrm{~kJ} / \mathrm{kg}$. A higher energy input of $8600 \mathrm{~kJ} / \mathrm{kg}$ resulted in a VBA yield of $86 \mathrm{wt} \%$, the maximum conversion possible in the particular cold, single-mode microwave cavity, without thermal insulation.

Electromagnetic field and thermal multiphysics' simulations complemented the experimental results, revealing a power density driven heating mechanism, favored by a high power input and short processing times. The non-thermal microwave-BA interactions generated localized microplasmas or hot spots that prompted BA melting at high heating rates. The high volumetric BA bulk temperatures achieved during processing, the intrinsic cold environment of the microwave cavity and the high silica content of BA, promoted a fast enough cooling of the melt and the production of highly amorphous VBA.

The leaching resistance of the VBA was successfully achieved from the microwave vitrification process. The exothermal response of the VBA upon alkali-activation suggests its potential to be used as precursor for alkali-activated materials, such as inorganic polymers.

\section{Acknowledgments}

This work was supported by the European Community's Horizon 2020 Programme under Grant Agreement No. 721185 (MSCA-ETN NEW-MINE). This publication reflects only the authors' view, exempting the Community from any liability. Project website: http://new-mine.eu/. G.Flesoura wishes to thank Mohamed Adam, Adam Buttress and Gabriela Durán-Jiménez for the help and support during the performed experiments at the University of Nottingham.

\section{References}

Alonso, S., Palomo, A., 2001. Calorimetric study of alkaline activation of calcium hydroxidemetakaolin solid mixtures. Cem. Concr. Res. 31, 25-30. https://doi.org/10.1016/S00088846(00)00435-X

Blasenbauer, D., Huber, F., Lederer, J., Quina, M.J., Blanc-biscarat, D., Bogush, A., Bontempi, E., Blondeau, J., Maria, J., Dahlbo, H., Fagerqvist, J., Giro-paloma, J., Hjelmar, O., Hyks, J., Keaney, J., Lupsea-toader, M., Simon, F., Svecova, L., Joyce, C., Caollai, O., Orupõld, K., Paja, T., Šyc, M., Ulvang, R., Vaajasaari, K., Caneghem, J. Van, Zomeren, A. Van, Vasarevic, S., Wégner, K., Fellner, J., 2020. Legal situation and current practice of waste incineration bottom ash utilisation in Europe 102, 868-883. https://doi.org/10.1016/j.wasman.2019.11.031

Coelho, A.A., 2016. TOPAS-Academic, Version 6: Technical Reference 208.

European Commission-Environment, 2019.2 Landfill waste. https://ec.europa.eu/environment/waste/landfill index.htm (accessed 17 January 2020).

European Parliament and Council, 2018. Directive (EU) 2018/851 of the European Parliament and of the council of 30 May 2018 amending Directive 2008/98/EC on waste. https://eurlex.europa.eu/legal-content/EN/TXT/PDF/?uri=CELEX:32018L0851\&from=EN (accessed 17 January 2020)

Ferrera-Lorenzo, N., Fuente, E., Suárez-Ruiz, I., Ruiz, B., 2014. KOH activated carbon from conventional and microwave heating system of a macroalgae waste from the Agar-Agar industry. Fuel Process. Technol. 121, 25-31. https://doi.org/10.1016/j.fuproc.2013.12.017

Flesoura, G., Garcia-Banos, B., Catala-Civera, J.M., Vleugels, J., Pontikes, Y., 2019a. In-situ 
measurements of high-temperature dielectric properties of municipal solid waste incinerator bottom ash. Ceram. Int. 45, 18751-18759. https://doi.org/10.1016/j.ceramint.2019.06.101

Flesoura, G., Peys, A., Vleugels, J., Pontikes, Y., 2019b. Alkali activation of synthetic $\mathrm{SiO}_{2}-\mathrm{CaO}-\mathrm{FeOx}-$ $\mathrm{Al}_{2} \mathrm{O}_{3}-\mathrm{MgO}$ glass, in: Malfiet, A., Peys, A., Di Maria, A. (Eds.), 6th International Slag Valorisation Symposium. Procopia, Mechelen, Belgium, pp. 345-348.

Gao, X., Yu, Q.L., Lazaro, A., Brouwers, H.J.H., 2017. Investigation on a green olivine nano-silica source based activator in alkali activated slag-fly ash blends: Reaction kinetics, gel structure and carbon footprint. Cem. Concr. Res. 100, 129-139. https://doi.org/10.1016/j.cemconres.2017.06.007

Hopwood, J., Hoskinson, A.R., Gregório, J., 2014. Microplasmas ignited and sustained by microwaves. Plasma Sources Sci. Technol. 23. https://doi.org/10.1088/0963-0252/23/6/064002

Hotta, M., Hayashi, M., Nagata, K., 2010. Complex Permittivity and Permeability of 50, 1514-1516.

Huang, Q., Cai, X., Du, C., Chi, Y., Yan, J., 2014. Thermal plasma vitrification of MSWI fly ash mixed with different biomass ashes. IEEE Trans. Plasma Sci. 42, 3549-3554. https://doi.org/10.1109/TPS.2014.2358626

Joseph, A.M., Snellings, R., Van den Heede, P., Matthys, S., De Belie, N., 2018. The use of municipal solidwaste incineration ash in various building materials: A Belgian point of view. Materials (Basel). 11. https://doi.org/10.3390/ma11010141

Kappe, C.O., 2013. How to measure reaction temperature in microwave-heated transformations. Chem. Soc. Rev. 42, 4977-4990. https://doi.org/10.1039/c3cs00010a

Kumar, S., Kumar, R., Mehrotra, S.P., 2010. Influence of granulated blast furnace slag on the reaction, structure and properties of fly ash based geopolymer. J. Mater. Sci. 45, 607-615. https://doi.org/10.1007/s10853-009-3934-5

Luukkonen, T., Abdollahnejad, Z., Yliniemi, J., Kinnunen, P., Illikainen, M., 2018. Comparison of alkali and silica sources in one-part alkali-activated blast furnace slag mortar. J. Clean. Prod. 187, 171-179. https://doi.org/10.1016/j.jclepro.2018.03.202

Menéndez, J.A., Arenillas, A., Fidalgo, B., Fernández, Y., Zubizarreta, L., Calvo, E.G., Bermúdez, J.M., 2010. Microwave heating processes involving carbon materials. Fuel Process. Technol. 91, 1-8. https://doi.org/10.1016/j.fuproc.2009.08.021

Menéndez, J.A., Juárez-Pérez, E.J., Ruisánchez, E., Bermúdez, J.M., Arenillas, A., 2011. Ball lightning plasma and plasma arc formation during the microwave heating of carbons. Carbon N. Y. 49, 346-349. https://doi.org/10.1016/j.carbon.2010.09.010

Mysen, B., Richet, M., 2005. Silicate Glasses and Melts, Properties and Structure, Elsevier S. ed. Elsevier Science.

Norm EN 12457-4, 2002.

Onisei, S., Lesage, K., Blanpain, B., Pontikes, Y., 2015. Early Age Microstructural Transformations of an Inorganic Polymer Made of Fayalite Slag. J. Am. Ceram. Soc. 98, 2269-2277. https://doi.org/10.1111/jace.13548

Robinson, J.P., Kingman, S.W., Lester, E.H., Yi, C., 2012. Microwave remediation of hydrocarboncontaminated soils - Scale-up using batch reactors. Sep. Purif. Technol. 96, 12-19. https://doi.org/10.1016/j.seppur.2012.05.020

Rosenholtz, J.L., Smith, D.T., 1936. The Dielectric Constant of Mineral Powders. Am. Mineral. 21, 115120.

Shang, H., Snape, C.E., Kingman, S.W., Robinson, J.P., 2006. Microwave treatment of oilcontaminated North Sea drill cuttings in a high power multimode cavity. Sep. Purif. Technol. 49, 84-90. https://doi.org/10.1016/j.seppur.2005.08.012

Sloot, H.A. Van Der, Kosson, D.S., Hjelmar, O., 2001. Characteristics, treatment and utilization of residues from municipal waste incineration. Waste Manag. 21, 753-765. https://doi.org/https://doi.org/10.1016/S0956-053X(01)00009-5

Stabile, P., Bello, M., Petrelli, M., Paris, E., Carroll, M.R., 2019. Vitrification treatment of municipal solid waste bottom ash. Waste Manag. 95, 250-258.

https://doi.org/10.1016/j.wasman.2019.06.021

Wei, Y., Shimaoka, T., Saffarzadeh, A., Takahashi, F., 2011. Alteration of municipal solid waste incineration bottom ash focusing on the evolution of iron-rich constituents. Waste Manag. 31, 1992-2000. https://doi.org/10.1016/j.wasman.2011.04.021 
Woollacott, L.C., Howat, D.D., Jochens, P.R., 1975. The viscosities and electrical conductivities of slags associated with the production of high-carbon ferromanganese alloys, in: Infacon (Ed.), The First International Ferroalloys Congress. Johannesburg, South Africa, pp. 227-232.

Xin-Hui, D., Srinivasakannan, C., Jin-Hui, P., Li-Bo, Z., Zheng-Yong, Z., 2011. Preparation of activated carbon from Jatropha hull with microwave heating: Optimization using response surface methodology. Fuel Process. Technol. 92, 394-400. https://doi.org/10.1016/j.fuproc.2010.09.033

Yuan, X., Qing, Q., Zhang, S., Lu, X., 2017. Vitrification of Radioactive Contaminated Soil by Means of Microwave Energy, in: AIP Conference Proceedings. American Institute of Physics (United States). https://doi.org/10.1063/1.4977304

Zhang, S., Ding, Y., Lu, X., Mao, X., Song, M., 2016. Rapid and efficient disposal of radioactive contaminated soil using microwave sintering method. Mater. Lett. 175, 165-168. https://doi.org/10.1016/j.matlet.2016.04.018 